\title{
Erratum to: Evaluation of cardiac functions in juvenile systemic lupus erythematosus with two-dimensional speckle tracking echocardiography
}

\author{
Reyhan Dedeoglu ${ }^{1}$ - Sezgin Şahin ${ }^{2} \cdot$ Aida Koka $^{1}$ - Funda Öztunç ${ }^{1}$ - Amra Adroviçç ${ }^{2}$ \\ Kenan Barut $^{2} \cdot$ Dicle Cengiz $^{3}$ • Özgür Kasapçopur ${ }^{2}$
}

Published online: 6 July 2017

(C) International League of Associations for Rheumatology (ILAR) 2017

Erratum to: Clin Rheumatol (2016) 35:1967-1975.

DOI 10.1007/s10067-016-3289-7.

The authors of the above article contacted the Journal on 29th March 2017, informing the Editor-in-Chief that they had discovered ethical approval was not requested from their Institutional Review Board (IRB) prior to performing the study discussed within the article. The authors explained that the omission of IRB approval resulted from miscommunication between the authorship group and a research fellow who left the group prior to the start of the study. Informed consent was received from all patients included in the study.

The authors subsequently submitted a retrospective ethics approval request to their IRB, which was approved on 8th May, 2017. Given the non-invasive nature of the study, the Editors decided that the course of action by the authors was satisfactory.

In the interests of transparency, the Journal and the authors wish to share the above with the Journal's readers.

The online version of the original article can be found at http://dx.doi.org/ $10.1007 / \mathrm{s} 10067-016-3289-7$

Reyhan Dedeoglu

reyhandedeoglu@gmail.com

Pediatric Cardiology, Cerrahpasa Medical Faculty, Department of Pediatric Cardiology, Istanbul University, Istanbul, Turkey

2 Pediatric Rheumatology, Cerrahpasa Medical Faculty, Department of Pediatric Cardiology, Istanbul University, Istanbul, Turkey

3 Department of Statistics, Istanbul Commerce University, Istanbul, Turkey 